\title{
Pilot Investigation of Perfluorinated Compounds in River Water, Sediment, Soil and Fish in Tianjin, China
}

\author{
Yuanyuan Pan $\cdot$ Yali Shi $\cdot$ Jieming Wang $\cdot$ \\ Xinglong Jin $\cdot$ Yaqi Cai
}

Received: 17 January 2011/Accepted: 13 May 2011/Published online: 28 May 2011

(C) Springer Science+Business Media, LLC 2011

\begin{abstract}
Detectable PFCs could be found in all samples. Perfluorooctanoic acid (PFOA) was the major PFC in river water, while perfluorooctane sulfonate (PFOS) was dominant in sediment and were 17- to 153-fold higher than those in water. PFCs concentrations in soil were little higher than those in sediment. In fish muscles PFOS showed the highest concentrations. Generally, PFC concentrations in fish were in the following rank order: crucian carp $>$ silver carp $>$ common carp. We suggested that there may be constant and diffuse pollution sources in Tianjin. Point sources also appeared to make significant contribution in the present study.
\end{abstract}

Keywords Perfluorinated compounds · Tianjin · Haihe River

Efforts have been taken to restrict the manufacturing and use of products containing perfluorinated compounds (PFCs) since 2000, however, these compounds are still widely used. Recent studies have detected trace levels of PFCs in blood/serum of general population in many

Electronic supplementary material The online version of this article (doi:10.1007/s00128-011-0313-0) contains supplementary material, which is available to authorized users.

Y. Pan · Y. Shi · J. Wang · Y. Cai (ه)

State Key Laboratory of Environmental Chemistry

and Ecotoxicology, Research Center for Eco-Environmental

Sciences, Chinese Academy of Sciences, 2871,

Beijing 100085, China

e-mail: caiyaqi@rcees.ac.cn

X. Jin

Department of Environmental Science and Safety Engineering,

Tianjin University of Technology, Tianjin 300191, China countries (Kannan et al. 2004), and in wildlife tissues around the world (Giesy and Kannan 2001). Both direct and indirect sources are suggested to account for the ubiquitous distribution of PFCs. The direct discharge of PFCs from industrial facilities or consumer products is supposed to be the major source of PFCs in the environment (mainly acids or salts). The potential precursor compounds are recognized as the indirect sources of PFCs, and they can be transformed to PFCs through subsequent degradation after released to the environment. It is proposed that water is the major medium for the transport of PFCs. There have been reports on the occurrence of PFCs contamination in surface water (Nakayama et al. 2007). Compared with water, much fewer studies have focused on the PFCs in environmental solid matrices. It is suggested that the losses of PFOA and PFOS in rivers are attributed to the sorption of sediment.

With the rapid economic growth, industrialization, and urbanization, Tianjin has become one of the most severely contaminated areas in China. The Haihe River flows through Tianjin city and into the Bohai Sea. Various pollutants, including some persistent organic pollutants (POPs), such as organochlorine pesticides (OCPs), have been detected in these rivers (Song et al. 2006). To our knowledge, no data is available for the contamination of PFCs in these rivers. The overall aim of this work was to conduct a pilot study to ascertain whether there is evidence of PFCs pollution in Tianjin. The contamination profiles and possible sources of PFCs were also discussed.

\section{Materials and Methods}

Sediment and river water samples were collected simultaneously on Dec 29-30 2008 from 23 sites along the Haihe 
River and Dagu Drainage River, Chentaizi Drainage River. Figure 1 shows the locations of sampling sites in Tianjin. More than 1-L water sample was collected from each sampling site with a stainless steel bucket that had been pre-cleaned with methanol, purified water and rinsed by the sample before collection. Water samples were then transferred to the lab, kept at $4^{\circ} \mathrm{C}$ and extracted within 1 week.

Sediment samples were collected with a stainless steel grab from the surface sediment $(0-5 \mathrm{~cm})$, then placed into polyethylene (PE) bags, frozen at $-20^{\circ} \mathrm{C}$ immediately on arriving at the laboratory. Then the sediments were freezedried, ground and passed through a 55-mesh sieve, and kept in PE bags until analysis.

Fishes including silver carp (Hypophthalmichthys molitrix $)(\mathrm{n}=5)$, crucian carp (Carassius auratus) $(\mathrm{n}=7)$ and common carp (Cyprinus carpio) $(\mathrm{n}=5)$ were obtained. Some of these fishes were collected in Haihe River simultaneously with the water collection. The others were got from a fishpond area in Xiqing District. Muscles were sampled and homogenated, and then freeze-dried for extraction and analysis.

Eighty-six soil samples were collected in agricultural area from suburb area of Tianjin, including the Xiqing District (23), Dongli District (22), Beichen District (19) and Jinnan District (22) (Fig. 1).

Water samples were filtered through nylon film $(0.45 \mu \mathrm{m})$ before extraction. An aliquot of $500 \mathrm{~mL}$ of the sample was spiked with $5 \mathrm{ng}$ of ${ }^{13} \mathrm{C}_{4}$-PFOS and ${ }^{13} \mathrm{C}_{4}$ PFOA, and then extracted with Oasis ${ }^{\circledR}$ Wax cartridge (6 cc, $150 \mathrm{mg}$; Waters Corp. Milford, USA). The eluate was then concentrated to $1 \mathrm{~mL}$ for injection. Sediment and soil samples were pretreated with methanol sonication method. One gram of the dry solid was sonicated in $5 \mathrm{~mL}$ of methanol at $60^{\circ} \mathrm{C}$ for $20 \mathrm{~min}$, and then the supernatant was collected after centrifugation. The same procedure was repeated for three times. The extract was further extracted with a HLB cartridge. The fish muscles were pretreated using the alkaline digestion method which has been described in our previous study (Shi et al. 2010).

The analysis of PFCs was performed on a liquid chromatograph with tandem mass spectrometer system as previously described (Shi et al. 2010). Generally, the separation was achieved on a Dionex Acclaim 120 C18 column $(4.6 \mathrm{~mm}$ i.d. $\times 150 \mathrm{~mm}$ length, $5 \mu \mathrm{m}$; Dionex, Sunnyvale, CA, USA) with an aliquot of $10 \mu \mathrm{L}$ injection. The identification of nine PFCs in samples was accomplished with an electrospray ionization tandem mass spectrometer (ESI/MS/MS; API3200, Applied Biosystems) operated in negative mode. Each sample was analyzed duplicate.

A nine point standard calibration was conducted for every batch of analysis $(20,50,100,200,1,000,5,000$, $10,000,20,000$ to $50,000 \mathrm{ng} / \mathrm{L}$ ). The calibration was conducted before each analysis. The method detection limits (LODs) were $0.014 \mu \mathrm{g} / \mathrm{L}$ for PFHxS, $0.015 \mu \mathrm{g} / \mathrm{L}$ for PFBS and PFOS, $0.1 \mu \mathrm{g} / \mathrm{L}$ for PFHpA and PFOA, $0.03 \mu \mathrm{g} / \mathrm{L}$ for PFNA, PFDA, PFUnDA, $0.04 \mu \mathrm{g} / \mathrm{L}$ for PFDoDA, $0.025 \mu \mathrm{g} / \mathrm{L}$ for PFTrDA and $0.05 \mu \mathrm{g} / \mathrm{L}$ for PFTA, respectively. Recoveries $(\mathrm{n}=4)$ from water, fish and sediment/ soil samples spiked with $2 \mathrm{ng}$ PFCs were 58-126\%, 68-109\% and $74-118 \%$, respectively, except PFTA in water $(31 \pm 2 \%, \mathrm{n}=4)$ and sediment $(31 \pm 4 \%, \mathrm{n}=4)$.

\section{Result and Discussion}

The PFC concentrations in river water are summarized in Table 1. PFCs (C4-C10) were detected in all the samples, revealing the wide occurrence of PFCs contamination in these rivers in Tianjin. In general, PFOA was the most prominent PFC in water in present study, followed by PFOS. The PFOA concentrations ranged from 4.77 to
Fig. 1 Location of sampling sites in rivers and suburban area in Tianjin. I: Beichen District; II: Dongli District; III: Xiqing District; $I V$ : Jinnan District. $B$ : Beiyunhe River; $Z$ : Ziyahe River; $N$ : Nanyunhe River; $H$ : Haihe River; $C$ : Chentaizi Drainage River; $D$ : Dagu Drainage River; $M$ : Machangjian River; Filled triangle: Sampling sites of water and sediment. Fishes were also collected at Site $2^{\#}, 4^{\#}, 6^{\#}$, $7^{\#}$, and $9^{\#}$ in Haihe River. Filled circle: Sampling sites of soil

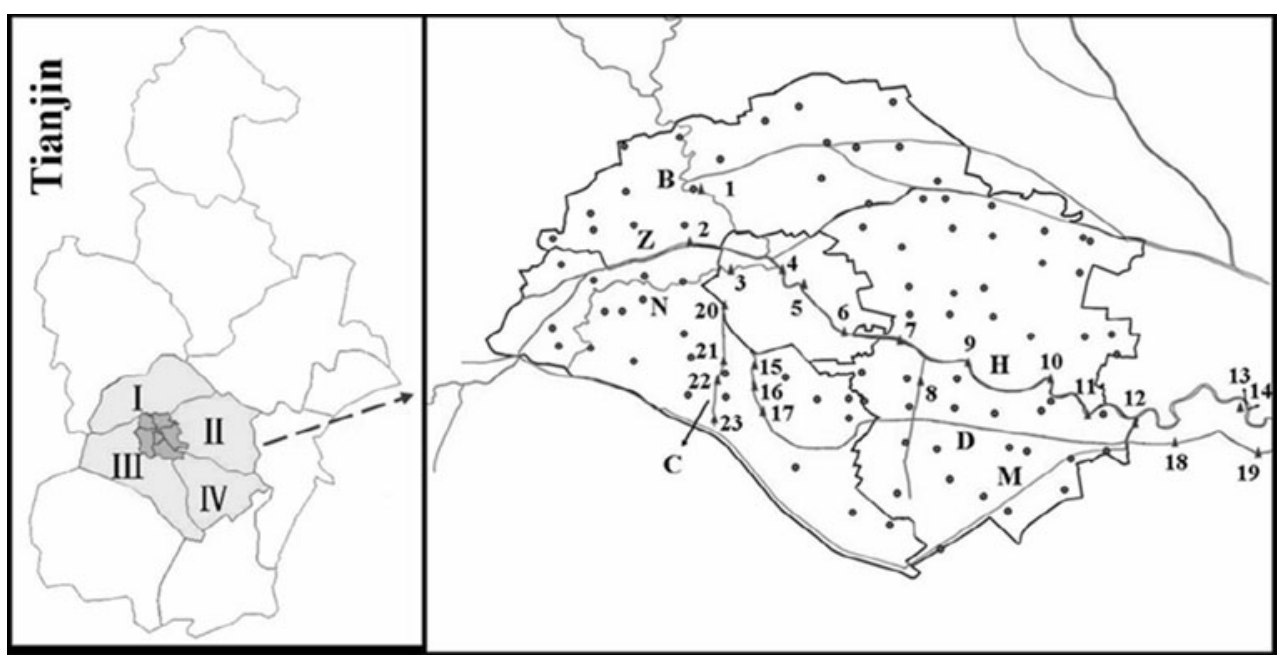


Table 1 PFC concentrations in river waters of Tianjin (ng/L)

\begin{tabular}{|c|c|c|c|c|c|c|c|c|c|}
\hline & & PFBS & PFHxS & PFHpA & PFOA & PFOS & PFNA & PFDA & PFUnDA \\
\hline \multicolumn{10}{|l|}{ Haihe River } \\
\hline \multirow[t]{3}{*}{ Tributary upstream } & W1 & 0.82 & 0.21 & 1.49 & 9.78 & 1.58 & 1.19 & 0.28 & $<0.06$ \\
\hline & W2 & 1.40 & 0.64 & 2.34 & 11.2 & 4.63 & 1.80 & 1.00 & 0.10 \\
\hline & W3 & 0.41 & 0.30 & 1.47 & 7.30 & 2.08 & 1.33 & 0.80 & 0.09 \\
\hline \multirow[t]{9}{*}{ Main stream } & W4 & 1.05 & 0.95 & 1.79 & 14.9 & 5.96 & 1.22 & 0.36 & $<0.06$ \\
\hline & W5 & 1.58 & 1.15 & 2.56 & 16.5 & 7.22 & 2.16 & 0.99 & 0.15 \\
\hline & W6 & 0.81 & 1.08 & 1.97 & 12.8 & 6.58 & 1.30 & 0.29 & 0.06 \\
\hline & W7 & 0.84 & 0.98 & 1.74 & 12.2 & 5.90 & 1.86 & 0.69 & $<0.06$ \\
\hline & W9 & 1.00 & 1.28 & 2.08 & 13.4 & 6.50 & 1.64 & 0.51 & 0.06 \\
\hline & W10 & 0.75 & 1.01 & 2.08 & 13.5 & 6.16 & 1.84 & 0.52 & $<0.06$ \\
\hline & W11 & 1.60 & 0.64 & 1.65 & 15.9 & 5.14 & 1.25 & 0.40 & 0.07 \\
\hline & W13 & 1.15 & 0.53 & 1.59 & 13.9 & 5.00 & 1.05 & 0.35 & $<0.06$ \\
\hline & W14 & 0.42 & 0.14 & 0.74 & 4.66 & 1.11 & 0.29 & 0.12 & $<0.06$ \\
\hline \multirow[t]{2}{*}{ Tributary downstream } & W8 & 1.79 & 0.62 & 1.49 & 12.0 & 5.64 & 1.40 & 0.42 & 0.10 \\
\hline & W12 & 1.32 & 0.78 & 2.09 & 22.9 & 7.65 & 1.32 & 0.54 & 0.09 \\
\hline \multicolumn{10}{|l|}{ Dagu Drainage River } \\
\hline & W15 & 0.06 & 0.28 & 1.06 & 8.81 & 2.21 & 10.6 & 0.80 & 0.07 \\
\hline & W16 & 1.14 & 0.32 & 1.29 & 9.55 & 2.02 & 1.13 & 0.58 & $<0.06$ \\
\hline & W17 & 0.23 & 0.17 & 0.39 & 5.84 & 2.22 & 0.88 & 0.42 & $<0.06$ \\
\hline & W18 & 15.9 & 0.59 & 2.59 & 19.2 & 11.0 & 11.5 & 3.82 & 0.49 \\
\hline & W19 & 8.04 & 0.76 & 1.78 & 14.7 & 7.28 & 6.24 & 1.79 & 0.20 \\
\hline \multicolumn{10}{|c|}{ Chentaizi Drainage River } \\
\hline & W20 & 0.33 & 0.28 & 1.15 & 8.47 & 1.99 & 1.12 & 0.59 & 0.30 \\
\hline & W21 & 0.79 & 0.19 & $<0.2$ & 7.76 & 1.63 & 1.00 & 0.56 & 0.35 \\
\hline & W22 & $<0.03$ & 0.35 & 1.43 & 11.2 & 1.98 & 1.50 & 0.70 & 0.21 \\
\hline & W23 & 2.55 & 0.42 & 1.31 & 9.00 & 1.68 & 1.41 & 0.71 & 0.20 \\
\hline
\end{tabular}

$22.9 \mathrm{ng} / \mathrm{L}$ (mean $12.1 \mathrm{ng} / \mathrm{L}$ ). The greatest concentration was found in W12 (Machangjian River), an important tributary in the downstream of Haihe River (Fig. 1). The lowest PFOA concentration was found in W14 (Fig. 1), which was located at the estuary of the Haihe River. Since there is a brake between before W14, we assumed that the decrease of PFOA concentration in W14 may be attribute to the dilution of the sea water. In the two tributaries in upstream of Haihe River, W1 and W2, PFOA concentrations were 9.78 and $11.2 \mathrm{ng} / \mathrm{L}$, respectively, implying that the river water was already polluted by PFCs before entering into the Haihe River.

In main stream of Haihe River, PFOA concentrations were in range of $12.2-16.5 \mathrm{ng} / \mathrm{L}$ (mean $14.1 \mathrm{ng} / \mathrm{L}$ ) (Table 1). PFOA concentrations were not found to decrease with the flow direction of the Haihe River (from west to east), which indicated constant pollution sources in this area. Moreover, the inflow of the two tributaries (W8 and W12) was not found to elevate PFOA concentrations. In the Dagu Drainage River, PFOA concentrations were from 5.84 to $19.2 \mathrm{ng} / \mathrm{L}$ (W15-W19) in water. PFOA concentrations were higher in W18 and W19 than those from upstream (W15-17) (Table 1), which indicated that some point sources should be responsible for the elevated PFOA concentrations. The Chentaizi Drainage River was not found serious PFOA contamination (7.76-11.2 ng/L), neither.

PFOS was the second dominant PFC in river water. In the two drainage rivers, the PFOS concentrations were generally 2-3 times lower than those of Haihe River suggesting there may be different sources of PFCs in Haihe River and drainage rivers. Other PFCs were also detected in waters of these rivers (Table 1). As to the profiles of PFCs in river water, little variation of the PFOA proportions existed in all samples of Haihe River (48.5-63.8\%) and Chentaizi Drainage River (52.1-64.5\%), While in Dagu Drainage River PFOA accounted for $29.4-59.4 \%$ of the $\sum$ PFCs. This can be conceivable evidence that there may be different sources of PFCs in Dagu Drainage River. Generally, concentrations of PFCs were relatively lower than those found in other studies. Nakayama et al. reported the PFOS and PFOA concentration at $30-127 \mathrm{ng} / \mathrm{L}$ and 47-287 ng/L in the Cape Fear River Basin (Nakayama et al. 2007). Higher PFOA levels were also reported in the 
Great Lakes and surface waters in New York State (Boulanger et al. 2004; Sinclair et al. 2006). In addition, the PFOA concentrations were similar to those observed in urban surface waters in Japan (Saito et al. 2004).

Significant positive correlations among PFC concentrations detected in Haihe River water (W1-W14) were observed. For example, statistically significant correlations were found among PFOA, PFOS, PFHxS and PFHpA $(p<0.05)$. In addition, PFCAs $(\mathrm{C} 7, \mathrm{C} 9-10)$ were also found significantly related with each other. The positive correlations probably indicated some common pollution sources of these compounds in Haihe River.

PFCs concentrations in fish muscle were presented based on wet weight (ESM: Table S1). PFOS was the dominant compound accounting for $27-73 \%$ of the total PFCs in fish muscle. This result was consistent with those observed in previous studies (Sinclair et al. 2006). Generally, the PFC concentrations in fish muscle were in the following rank order: crucian carp $>$ silver carp $>$ common carp. Fishes collected in Haihe River were found higher PFC concentrations than those collected from fishpond. For crucian carp, PFOS concentrations in samples collected in Haihe River were 0.58-9.04 ng/g (median 6.36 ng/g) (wet wt) $(\mathrm{n}=5)$, while in samples from the fishpond PFOS concentrations were 1.19-2.10 ng/g $(\mathrm{n}=2)$, wet wt. PFOS concentration was $3.21 \mathrm{ng} / \mathrm{g}$ in silver carp muscle from Haihe River, which was 3.9-5.3 times of those from the fishpond, while for common carp, the PFOS concentration were 7.7-14 times higher. Compared with previous studies, PFOS concentrations were much lower in present study. Ye et al. (2008) reported the PFOS concentrations in range of 11-90 ng/g (wet wt) in common carp fillets collected from areas of the Mississippi River. In addition, Giesy and Kannan also reported PFOS concentrations in carp muscle in range of 60-300 ng/g (wet wt) collected from Saginaw Bay, Michigan (Giesy and Kannan 2001).

Perfluoroalkyl acids (PFCAs) with longer-chain $(\mathrm{C}>8)$ were also detected in fishes, and the concentrations were sometimes higher than those of PFOA. It is assumed that PFCAs with longer-chain may tend to be more accumulative in organisms and thus exhibit higher concentrations. Moreover, researches have revealed that some precursors such as fluorotelomer alcohols (FTOH) could be biodegraded to PFDA and PFUnDA, which can be another potential source.

Based on the PFC concentrations in Haihe River water and fish muscles (wet wt), the bioconcentration factors (BCF) were calculated for crucian carp, silver carp and common carp in present study. Previous studies have demonstrated that PFOS is preferably concentrated in liver, and most of previous studies paid their attention to the bioaccumulation of PFCs in fish liver. However, PFC concentrations in liver were not analyzed. In present study, BCF values for PFOS ranged from 97 to 1,391 (mean 816).
These BCF values are lower than those of in Great Lake fish muscles reported by Boulanger et al. (2004). Martin et al. (2003) has reported that BCFs for PFCAs (C8-C12) yielded from an exposed experiment based on rainbow trout showed an increase with increasing length of the perfluoroalkyl chain. Similar trend was also observed for in present study, indicating the analyses of longer chain acids should be also more concentrated.

Eighteen sediment samples were analyzd in present study. Generally PFOS was the prominent PFC in sediment (Table S2). All sediments could be found measurable PFOS. In Haihe River (S1-S14), the PFOS concentrations were in range of $0.15-0.79 \mathrm{ng} / \mathrm{g}$ (dry wt) (except S14), which were much lower than those reported in an earlier study performed in Shanghai ( $\mathrm{Li}$ et al. 2010). PFOS concentrations $(0.028-0.29 \mathrm{ng} / \mathrm{g}$, dry wt) were a little lower in sediment of Drainage Rivers than Haihe River, indicating that wastewater discharged into the two drainage rivers did not significantly influence the PFOS concentrations in sediments. However, in the upstream of the two drainage rivers, S15 and S20, PFOS was found at the lowest concentrations compared with other sites of the two drainage rivers. This is another conceivable evidence of the assumption that wastewaters already polluted by PFOS are discharged into the rivers in the areas where they flow through. Bao et al. (2009) has previous reported similar PFOS and PFOA levels in sediment of Daliao River system in Liaoning, China. When compared with other regions over the world, the sediment levels were also much lower than those from Ariake Sea in Japan (Nakata et al. 2006).

PFOA concentrations were much lower than PFOS. In Haihe River, PFOA concentrations were ND- 0.25 ng/g, dry wt, while in Dagu Drainage River and Chentaizi Drainage River the concentrations were $0.04-0.90$ and $0.06-0.40 \mathrm{ng} /$ g, dry wt, respectively. However, relatively higher concentrations of PFOA than PFOS were found in some sampling sites of the Drainage Rivers (S15, S20 and S23). Several previous studies have also reported higher PFOA concentrations than PFOS in sediment. For example, Nakata et al. measured PFOS and PFOA concentrations at $0.09-0.14 \mathrm{ng} / \mathrm{g}$ and $0.84-1.1 \mathrm{ng} / \mathrm{g}$ (wet weight) in sediments from the Ariake Sea in Japan (Nakata et al. 2006). In Shanghai PFOA concentrations were in range of 5.20-203 ng/g, which were higher than PFOS ( $\mathrm{Li}$ et al. 2010). The authors attributed the higher level of PFOA to the more PFOA entering in water bodies. Furthermore, PFHpA and some long-chain PFCAs (C9-C12) were also detected in some sediment samples and their concentrations were even higher than PFOA and PFOS in some individual cases. We assumed that this should be owing to the point sources nearby.

Because of the low detect frequency of PFOA in sediment, PFOS concentrations relative to the respective water 
Table 2 PFC concentrations in soil from for suburban districts of Tianjin (ng/g dry wt)

\begin{tabular}{|c|c|c|c|c|c|c|c|c|}
\hline & & PFHxS & PFHpA & PFOA & PFOS & PFNA & PFDA & PFUnDA \\
\hline \multirow[t]{4}{*}{ Xiqing District } & Mean & 0.40 & 0.13 & 0.27 & 0.41 & 0.081 & 0.060 & $<0.03$ \\
\hline & Min & $<0.014$ & $<0.1$ & $<0.1$ & 0.049 & $<0.03$ & $<0.03$ & $<0.03$ \\
\hline & Max & 5.86 & 0.29 & 0.51 & 1.42 & 0.20 & 0.19 & 0.068 \\
\hline & Median & 0.04 & 0.10 & 0.25 & 0.34 & 0.068 & 0.055 & 0.036 \\
\hline \multirow[t]{4}{*}{ Dongli District } & Mean & 0.36 & 0.16 & 0.19 & 0.22 & 0.13 & $<0.03$ & $<0.03$ \\
\hline & Min & $<0.014$ & $<0.1$ & $<0.1$ & 0.023 & $<0.03$ & $<0.03$ & $<0.03$ \\
\hline & $\operatorname{Max}$ & 5.86 & 0.92 & 0.50 & 1.21 & 0.69 & 0.12 & 0.10 \\
\hline & Median & $<0.014$ & $<0.1$ & 0.17 & 0.16 & 0.083 & $<0.03$ & $<0.03$ \\
\hline \multirow[t]{4}{*}{ Jinnan District } & Mean & 0.29 & $<0.1$ & 0.16 & 0.39 & 0.032 & 0.030 & $<0.03$ \\
\hline & Min & $<0.014$ & $<0.1$ & $<0.1$ & 0.043 & $<0.03$ & $<0.03$ & $<0.03$ \\
\hline & Max & 2.40 & 0.16 & 0.33 & 2.30 & 0.064 & 0.082 & 0.048 \\
\hline & Median & 0.036 & $<0.1$ & 0.16 & 0.18 & 0.026 & $<0.03$ & $<0.03$ \\
\hline \multirow[t]{4}{*}{ Beichen District } & Mean & 0.12 & $<0.1$ & 0.15 & 0.28 & 0.055 & 0.047 & $<0.03$ \\
\hline & Min & $<0.014$ & $<0.1$ & $<0.1$ & 0.046 & $<0.03$ & $<0.03$ & $<0.03$ \\
\hline & Max & 0.77 & 0.27 & 0.26 & 2.36 & 0.14 & 0.13 & 0.055 \\
\hline & Median & 0.045 & $<0.1$ & 0.16 & 0.12 & 0.050 & 0.036 & $<0.03$ \\
\hline
\end{tabular}

samples were evaluated in these three rivers. PFOS concentrations in sediment were 17- to 153-fold higher than concentrations determined in the corresponding water samples. However, PFOS concentrations in sediment from Haihe River were not found to be significantly related to those in river water.

All soil samples could be found detectable PFCs (Table 2). Generally, PFOS is the dominant PFC in soil samples collected in the four districts, followed by PFOA. PFOS concentrations were in range of $0.023-2.36 \mathrm{ng} / \mathrm{g}$ (median 0.19) (dry wt), while PFOA in range of ND$0.51 \mathrm{ng} / \mathrm{g}$ (median 0.19) (dry wt). Among the four districts, Xiqing District was found the greatest PFOS concentrations, followed by Jinnan and Dongli, while the lowest in Beichen District. PFOA concentrations were in similar levels in Jinnan, Dongli and Beichen District, which were slightly lower than those in Xiqing District. PFHxS, PFHpA and PFNA were also detected in soil. Notably, the concentrations of PFHxS and PFHpA were much higher than PFOA and PFOS in some individual samples (Table 2), which may be due to the influence of point sources near the sampling sites. The concentrations of PFHpA were generally higher than PFNA. In China, only one paper has reported PFC concentrations in soil of Shanghai (Li et al. 2010). PFOS and PFOA concentrations in soil collected in Shanghai were $8.58-10.4 \mathrm{ng} / \mathrm{g}$ and 3.28-47.5 ng/g, respectively, which were much higher than results detected in present study. Furthermore, Li et al. also found trifluoroacetic acid (TFA) as the major PFC detected in soil in Shanghai, which accounted for $>60 \%$ of PFCs ( $\mathrm{Li}$ et al. 2010), however, TFA was not analyzed in present study.
Two possible reasons will explain the PFCs contamination in soil of the agricultural land in Tianjin. The first one is through the irrigation using the water already polluted by PFCs; the other reason is that some chemicals and their precursors in the atmosphere may be washed down to the ground by precipitation, and then degraded into PFCAs in soil (Liu et al. 2007). PFOA concentrations were significantly correlated with PFOS and PFDA. Besides, significant correlations were also found between PFHpA and PFNA. This indicated that these compounds may have a common source or similar transformation mechanism in soil. However, some studies showed that PFCs such as PFOA will not significantly retained by geo-solids, once they are emitted to land, they will be rapidly transferred to surface water or shallow groundwater (Davis et al. 2007) and ultimately to the oceans. Thus, a long-term study is essential to get well knowledge of the PFCs contamination in soil in Tianjin.

Acknowledgments This work was jointly supported by the HighTechnology Research and Development Program of China (2007AA06Z405), the National Natural Science Foundation of China (No. 20907063, 20837003, 20890111), the National Basic Research Program of China (2009CB421605) and the Department of Public Welfare research projects of environmental protection industry (2010467026).

\section{References}

Bao J, Jin YH, Liu W, Ran XR, Zhang ZX (2009) Perfluorinated compounds in sediments from the Daliao River system of northeast China. Chemosphere 77:652-657 
Boulanger B, Vargo JD, Schnoor JL, Hornbuckle KC (2004) Detection of perfluorooctane surfactants in Great Lakes Water. Environ Sci Technol 38:4064-4070

Davis KL, Aucoin MD, Larsen BS, Kaiser MA, Hartten AS (2007) Transport of ammonium perfluorooctanoate in environmental media near a fluoropolymer manufacturing facility. Chemosphere 67:2011-2019

Giesy JP, Kannan K (2001) Global distribution of perfluorooctane sulfonate in wildlife. Environ Sci Technol 35:1339-1342

Kannan K, Corsolini S, Falandysz J, Fillmann G, Kumar KS, Loganathan BG (2004) Perfluorooctanesulfonate and related fluorochemicals in human blood from several countries. Environ Sci Technol 38:4489-4495

Li F, Zhang CJ, Qu Y, Chen J, Chen L, Liu Y (2010) Quantitative characterization of short- and long-chain perfluorinated acids in solid matrices in Shanghai, China. Sci Total Environ 408:617-623

Liu J, Lee LS, Nies LF, Nakatsu CH, Turco RF (2007) Biotransformation of 8: 2 fluorotelorner alcohol in soil and by soil bacteria isolates. Environ Sci Technol 41:8024-8030

Martin JW, Mabury SA, Solomon KR, Muir DCG (2003) Bioconcentration and tissue distribution of perfluorinated acids in rainbow trout (Oncorhynchus mykiss). Environ Toxicol Chem 22:196-204

Nakata H, Kannan K, Nasu T, Cho H-S, Sinclair E, Takemura A (2006) Perfluorinated contaminants in sediments and aquatic organisms collected from shallow water and tidal flat areas of the Ariake Sea, Japan: environmental fate of perfluorooctane sulfonate in aquatic ecosystems. Environ Sci Technol 40: 4916-4921

Nakayama S, Strynar MJ, Helfant L, Egeghy P, Ye X, Lindstrom AB (2007) Perfluorinated compounds in the cape fear drainage basin in North Carolina. Environ Sci Technol 41:5271-5276

Saito N, Harda K, Inoue K, Sasaki K, Yoshinaga T, Koizumi A (2004) Perfluorooctanote and perfluorooctane sulfonate concentrations in surface water in Japan. J Occup Health 46:49-59

Shi Y, Pan Y, Yang R, Wang Y, Cai Y (2010) Occurrence of perfluorinated compounds in fish from Qinghai-Tibetan Plateau. Environ Int 36:46-50

Sinclair E, Mayack DT, Roblee K, Yamashita N, Kannan K (2006) Occurrence of perfluoroalkyl surfactants in water, fish, and birds from New York State. Arch Environ Con Tox 50:398-410

Song M, Jiang Q, Xu Y, Liu H, Lam PKS, O'Toole DK (2006) AhRactive compounds in sediments of the Haihe and Dagu Rivers, China. Chemosphere 63:1222-1230

Ye XB, Schoenfuss HL, Jahns ND, Delinsky AD, Strynar MJ, Varns J (2008) Perfluorinated compounds in common carp (Cyprinus carpio) fillets from the upper Mississippi River. Environ Int 34:932-938 